\title{
Correction to: Interactional spaces of a high-rise group housing complex and social cohesion of its residents: case study from Kolkata, India
}

\author{
Soumi Muhuri ${ }^{1}$ (D) Sanghamitra Basu ${ }^{2}$
}

Published online: 28 April 2021

(c) Springer Nature B.V. 2021

\section{Correction to: Journal of Housing and the Built Environment https://doi.org/10.1007/s10901-021-09830-3}

In the original publication of the article, the heading of the Table 1 was incorrectly published as "Sense of belonging to a group (Cronbach's alpha $=0.889$, composite reliability = 0.890)". However, it is intended only for the first nine entries. The correct heading of the Table 1 is "Dimensions/Sub-dimensions" and the corrected Table 1 is given below.

The original article has been corrected.

The original article can be found online at https://doi.org/10.1007/s10901-021-09830-3.

Soumi Muhuri

muhurisoumi@gmail.com

Sanghamitra Basu

s.basu.arp@gmail.com

1 Department of Planning and Architecture, National Institute of Technology, Rourkela, Odisha 769008, India

2 Department of Architecture and Regional Planning, Indian Institute of Technology, Kharagpur, West Bengal 721302, India 


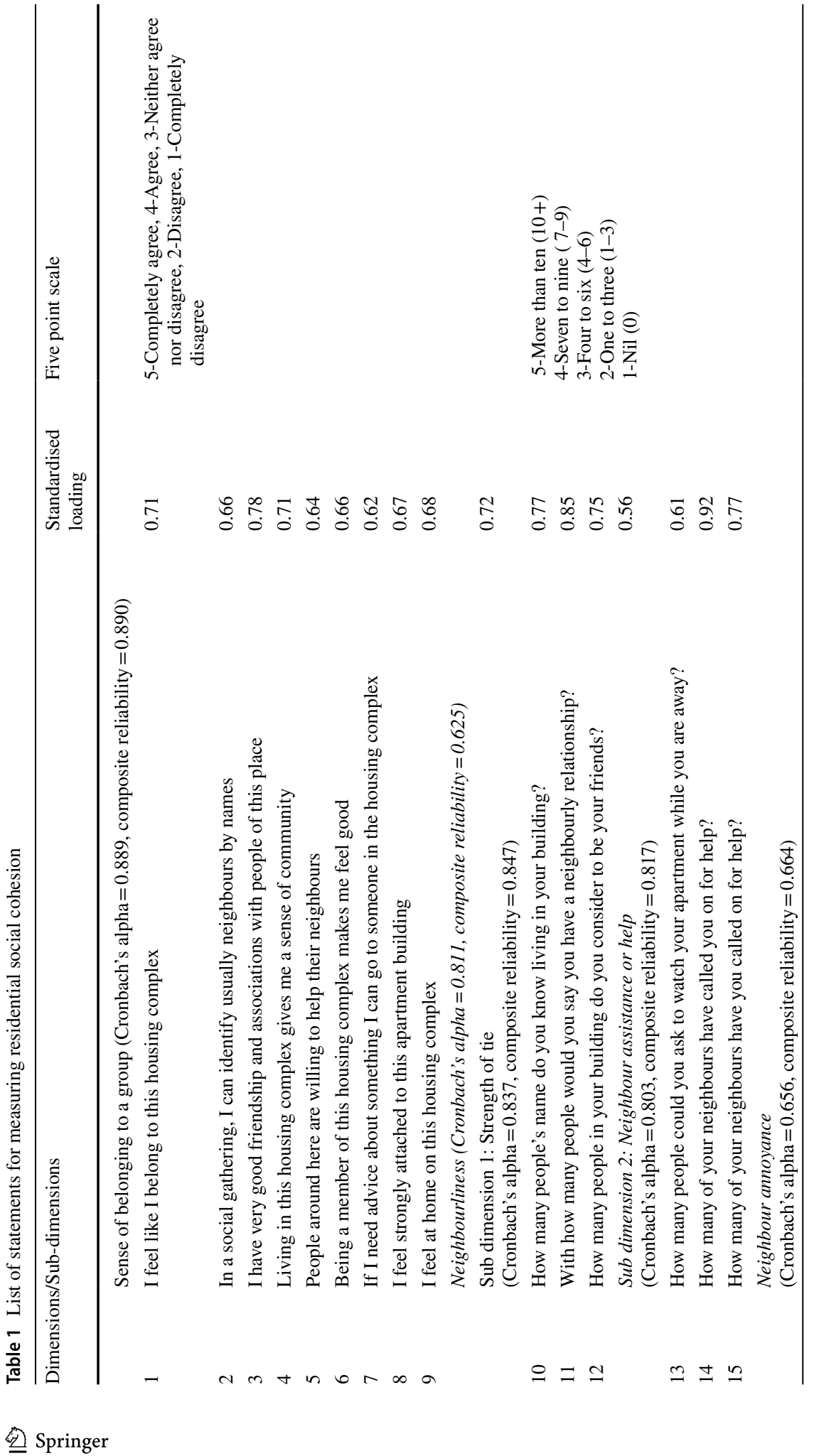




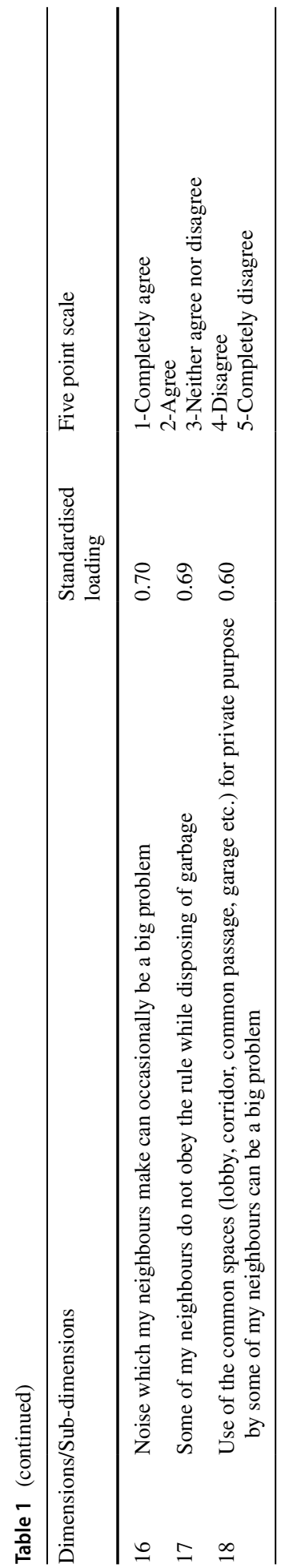


Publisher's Note Springer Nature remains neutral with regard to jurisdictional claims in published maps and institutional affiliations. 